
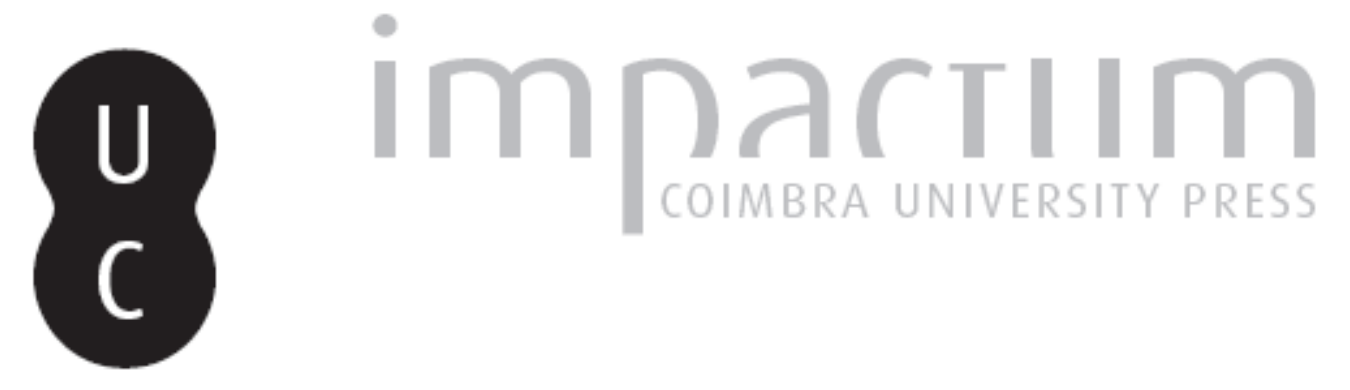
Provedores da Santa Casa da Misericórdia de Arganil do século XIX: metamorfoses,
elos e poderes
Autor(es):
Formigo, Filipa

Publicado por: Centro de História da Sociedade e da Cultura

URL persistente:

URI:http://hdl.handle.net/10316.2/39530

DOI:

DOI:http://dx.doi.org/10.14195/1645-2259_10-2_4

Accessed : $\quad$ 26-Apr-2023 11:15:37

A navegação consulta e descarregamento dos títulos inseridos nas Bibliotecas Digitais UC Digitalis, UC Pombalina e UC Impactum, pressupõem a aceitação plena e sem reservas dos Termos e Condições de Uso destas Bibliotecas Digitais, disponíveis em https://digitalis.uc.pt/pt-pt/termos.

Conforme exposto nos referidos Termos e Condições de Uso, o descarregamento de títulos de acesso restrito requer uma licença válida de autorização devendo o utilizador aceder ao(s) documento(s) a partir de um endereço de IP da instituição detentora da supramencionada licença.

Ao utilizador é apenas permitido o descarregamento para uso pessoal, pelo que o emprego do(s) título(s) descarregado(s) para outro fim, designadamente comercial, carece de autorização do respetivo autor ou editor da obra.

Na medida em que todas as obras da UC Digitalis se encontram protegidas pelo Código do Direito de Autor e Direitos Conexos e demais legislação aplicável, toda a cópia, parcial ou total, deste documento, nos casos em que é legalmente admitida, deverá conter ou fazer-se acompanhar por este aviso. 


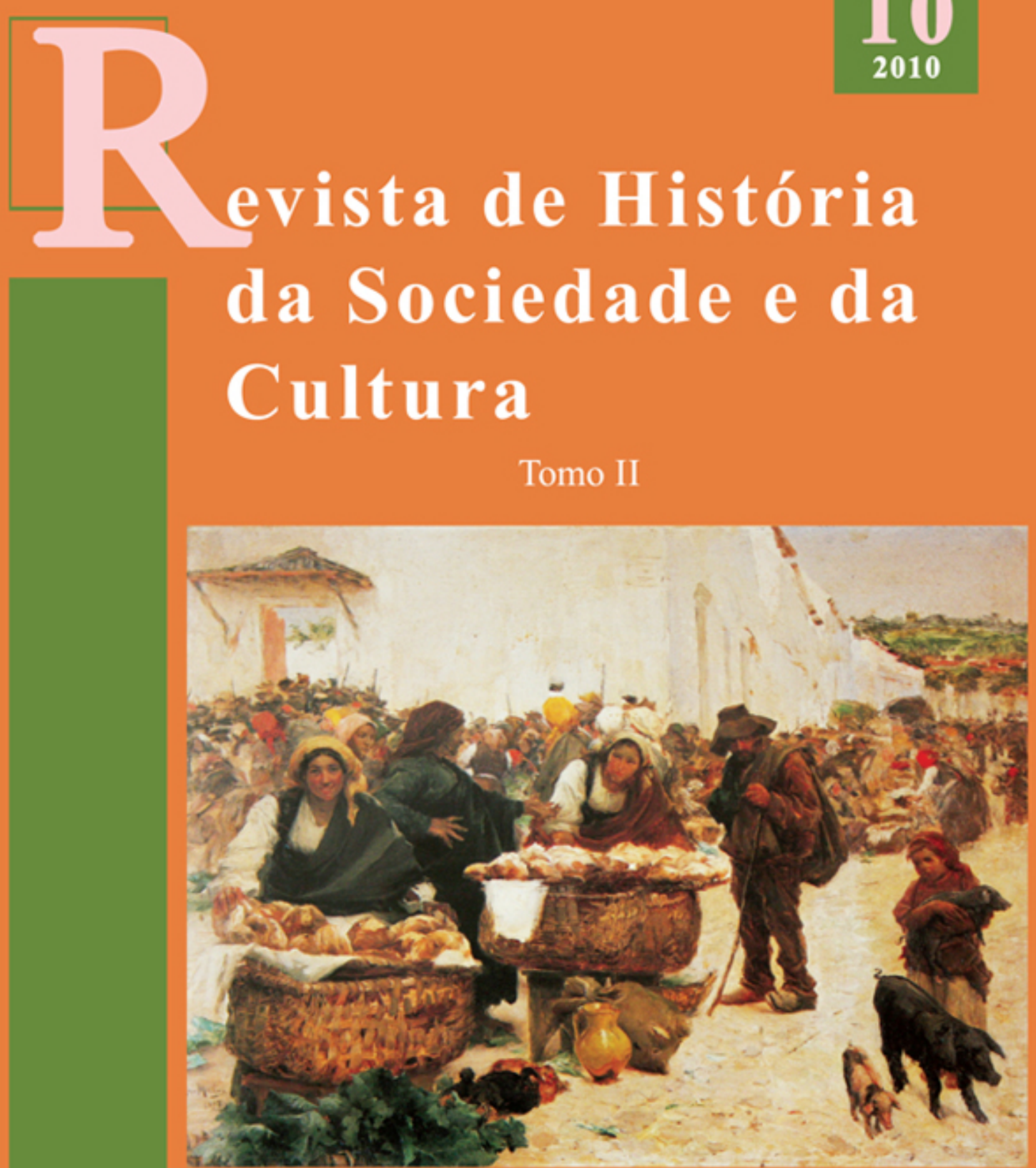

Centro de História da Sociedade e da Cultura Universidade de Coimbra

Coimbra 


\title{
Provedores da Santa Casa da Misericórdia de Arganil do século XIX. Metamorfoses, elos e poderes*
}

\author{
Filipa Formigo \\ Licenciada em História pela Universidade de Coimbra \\ filipaf05@gmail.com \\ Texto recebido em/ Text submitted on: 24/02/2010 \\ Texto aprovado em/ Text approved on: 07/05/2010
}

\section{Resumo/Abstract:}

Neste artigo propõe-se um estudo de natureza prosopográfica em torno das elites locais chamadas ao poder da Santa Casa da Misericórdia de Arganil, salientando esta no contexto das Misericórdias Portuguesas do século XIX, os provedores dirigentes no mesmo período e as suas relações, poderes e conflitualidades. No século XIX, a Misericórdia de Arganil revela um evidente papel social na transmissão de influência e prestígio às elites locais, verificando-se uma gradual ruptura da hegemonia nobiliárquica e a ascensão de categorias profissionais com estatuto dignificante o que se traduz na emergência de conflitualidade pelo clero, grupo de maior domínio durante o período em análise.

This paper undertakes to study from a prosopographic perspective the local elites who were summoned to lead the Santa Casa da Misericórdia (Holy House of Mercy) of Arganil, against the backdrop of 19th century Portuguese Misericórdias, while focusing on the chairing ombudsmen and relevant connections, powers and conflicts. In the 19th century, Misericórdia of Arganil manifestly plays a social role in the transfer of power and prestige to the local elites, hereby witnessing a growing break in the hegemony of the nobility and the rise of professional categories which enjoyed a dignifying status, consequently originating conflicts among the clergy, the dominant social group at the time.

Palavras chave/Keywords:

Misericórdia; Arganil; Provedores; Elite; Poder local.

Misericórdia; Arganil; Ombudsmen; Elite; Local power.

* Este texto corresponde ao trabalho realizado no âmbito de um seminário da Licenciatura em História da FLUC, orientado pela Professora Doutora Maria Antónia Lopes. Agradeço a todos os que, directa ou indirectamente, contribuíram para a sua realização. À Professora Doutora Maria Antónia Lopes, pela orientação dedicada e pelo constante estímulo nesse $2^{\circ}$ semestre de 2008-2009. Ao senhor Provedor da Santa Casa da Misericórdia de Arganil, professor José Dias Coimbra, por me ter permitido o acesso a toda a documentação do Arquivo da Santa Casa. Ao senhor Director Geral da Santa Casa da Misericórdia de Arganil, Dr. Nuno Miguel Gomes, devido ao apoio e disponibilidade prestadas. À Professora Doutora Regina Anacleto, pelo olhar crítico e pelas suas recomendações. Ao senhor Jorge Pereira, pela atenção e amabilidade com que me recebeu e encaminhou na Biblioteca Municipal de Arganil. 


\section{Introdução}

As elites superintendentes da Santa Casa da Misericórdia de Arganil, mais concretamente os provedores, enquanto protagonistas da vida social arganilense do século XIX e, ao mesmo tempo, membros de uma poderosa organização promotora de estatuto social, são o tema principal do trabalho que se pretende desenvolver.

Sendo as misericórdias instituições que, pelos seus ricos séculos de história, atravessaram conjunturas das mais diversificadas que as obrigaram a mudanças que ditaram a sua sobrevivência, e sendo o século XIX um período de profundas mudanças no país, será interessante analisar de que forma essas progressivas alterações chegaram a um âmbito local manifestando-se também nas misericórdias. Para explorar esse objectivo, o ponto 1 será de contextualização histórica das Santas Casas no século XIX, a de Arganil em particular, a par das circunstâncias gerais condicionantes, sejam elas locais ou globais.

A caracterização do perfil dos provedores permite-nos questionar a capacidade selectiva da instituição. Para isso, será essencial perceber quais as características que se revelavam imprescindíveis a esse cargo, o que seria exigido na escolha do mais alto representante da instituição. Todavia, terá existido um grupo maioritariamente dominante? E que implicações houve para a direcção da Misericórdia? Será, neste caso, essencial um estudo prosopográfico dos provedores apurando qual o grupo social a que pertenciam, em que sector profissional estavam inseridos ou que tipo de formação detinham. Para tal, foi efectuada uma análise às diferentes fases que ditam as mais significativas mudanças a esse nível, durante todo século. Sendo que estas são determinadas pelo tipo de motivações para o cargo, um aspecto indispensável para compreender quaisquer alterações. Desta forma, o segundo ponto pretende abordar a temática dos provedores dirigentes da Santa Casa ao nível das suas funções, do seu poder simbólico e dos grupos sociais abrangidos.

Perante as problemáticas colocadas, outras, que permitem entender mais concretamente o grupo de provedores analisados, serão focadas no âmbito das relações que se estabeleceram. Existiria ou não uma oligarquia dominante, quer entre o cargo de provedor, quer entre outros cargos da mesa? Era notória 
uma rede familiar? Para responder a estas questões é preponderante uma análise à rotatividade dos cargos e mandatos, correspondente à primeira parte do ponto 3. Uma das relações que se salienta como foco de observação, é a que existiria entre a Câmara e a Misericórdia. Seriam ou não duas instituições sem qualquer vínculo ao nível da sua liderança?

No entanto, sendo a Misericórdia uma instituição das mais poderosas ao nível local, não seria também um pólo gerador de conflitos? Em que é que consistiriam? As respostas a essas questões são o objectivo da última parte do terceiro ponto.

\section{Misericórdia de Arganil no contexto das misericórdias portuguesas no século XIX}

Nos finais do século XVIII, inícios do século XIX, a inflação foi violenta em Portugal. O país deparava-se com uma crise alimentar e comercial ${ }^{1}$ provocada pela abertura dos portos brasileiros ao livre comércio, pelas ocupações estrangeiras a partes do Ultramar, por um comércio externo perturbado e por uma indústria em baixa produção. Estes factores levaram a um saldo negativo da balança comercial, a uma elevada subida dos preços e a que as finanças do Estado se afigurassem deficitárias, provocando, naturalmente, fortes impactos na economia nacional. Este panorama, em si prejudicial ao país, foi agravado pelo distanciamento do governo da cidade de Lisboa, transformando Portugal «numa colónia do Brasil e num protectorado da Grã-Bretanha $»^{2}$. Agravamento este ocasionado pelo contexto de sete anos de guerra com três invasões francesas.

Cada região do país sofreu as consequências tanto da crise como da guerra, que chegaram também às Santas Casas ${ }^{3}$. Rui Cascão conclui que

1 MARQUES, A. H. Oliveira - Conjuntura in MARQUES, A. H. Oliveira (coord.) Portugal e a Instauração do Liberalismo, vol. IX de Nova História de Portugal dir. por Joel Serrão e A. H. Oliveira Marques. Lisboa: Editorial Presença, 2002, p. 544-607.

2 Idem, ibidem, p. 545.

3 SÁ, Isabel dos Guimarães e LOPES, Maria Antónia-História Breve das Misericórdias Portuguesas. Coimbra: Imprensa da Universidade de Coimbra, 2008, p. 74-80. 
Arganil foi «uma das zonas mais afectadas dentro do Bispado de Coimbra $»^{4}$ especialmente pela terceira invasão francesa, o que irá reflectir-se nas actividades usuais da Misericórdia, como se pode ler em assento de 1 de Julho de 1811:

«Determinou-se que em atenção ao compormisso pelo qual se devia hoje proceder a Eleição do Provedor e Officiaes, a que pelos tristes circunstancias dos tempos occazionados da guerra se não apresentarão todos os indivíduos necessarios para ella, ficasse servindo por aclamação o mesmo senhor Provedor e mais Officiaes e Irmãos da meza $)^{5}$.

A estes acontecimentos seguiu-se a revolução liberal de 1820 e a contra-revolução. O período que se segue, de governação miguelista, vai caracterizar-se por um reforço do exército e por constantes actos repressivos. O que justifica que na acta da mesa da Misericórdia de Arganil de 1 de Junho de 1828 se refira que não teve efeito a mesma reunião por «se nam poder fazer por cauza do barulho que hove com a entrada da tropa $\rangle^{6}$.

A guerra civil de 1832 a 1834 teve fortes impactos e aprofundou a crise financeira. Com a Regeneração, em 1851, o país conseguiu alcançar alguma estabilidade. Entre 1870 e 1890 foi possível estabelecer-se uma "democratização" gradual e um equilíbro entre os poderes. No entanto, importa não esquecer as dificuldades com a questão da Índia (1871), a questão ibérica (1869-1874) e a questão de Lourenço Marques (1872-1875). Na sequência do Ultimatum de 1890, as relações com Inglaterra degradaram-se e de norte a sul do país, principalmente nas grandes cidades, surgiram revoltas ${ }^{7}$.

A situação em que as misericórdias se encontravam no final do século XVIII, que se vai reflectir na centúria seguinte, era uma continuação das dificuldades sentidas em anos anteriores, restringindo-se essencialmente ao

${ }^{4}$ CASCÃO, Rui - Aspectos sociais e económicos do concelho de Arganil na segunda metade do século XIX. Boletim do Arquivo da Universidade. 4 (1978), 1-37.

5 Arquivo da Santa Casa da Misericórdia de Arganil (ASCMA), Eleições e determinações, livro 1, fl. 31v-32.

${ }^{6}$ ASCMA, Eleições e determinações, livro 1, fl. 140v.

7 MARQUES, A. H. Oliveira - Conjuntura, cit. 
contínuo e cada vez maior número de dívidas activas ${ }^{8}$. Esta conjuntura foi provocada pelo capital que, na maioria dos casos, era creditado a pessoas de maior estatuto local e que não pagando os juros do empréstimo, não tinham quem lhes exigisse o pagamento, devido ao seu poder de influência. $\mathrm{Na}$ Misericórdia de Arganil estas dificuldades vão fazer-se sentir também em meados do século XIX, como transparece na acta de 14 de Março de 1847: «Que attendendo ao estado de penuria em que se acha a Santa Caza da Mesericordia pois naõ tem dinheiro no cofre por falta de pagamentos pelos devedores ${ }^{9}$.

Outro aspecto que justifica algumas das dificuldades financeiras internas é a sucessiva diminuição dos rendimentos dos enterros pelo desenvolvimento de outras confrarias e ordens terceiras. Aliado a essas dificuldades existia ainda um elevado número de encargos pios, sonegação de bens, desmazelo e fraudes administrativas, diminuição das rendas devido à subida dos preços e crescimento das despesas pelo aumento da procura por parte das populações ${ }^{10}$.

No entanto, apesar das dificuldades acrescidas, surgiram ao mesmo tempo novos serviços. Este facto levou Maria Antónia Lopes a defender um carácter não totalizador da crise nestas instituições ${ }^{11}$. O mesmo afirma Luís Elias, que caracteriza o período como sendo de adaptação ou refundação das mesmas ${ }^{12}$.

Outro factor a destacar da conjuntura interna das misericórdias no período considerado, é o reforço da intervenção da Coroa, com o desígnio de evitar hegemonias do poder local e o desrespeito por determinadas normas ao nível financeiro, regulamentar e administrativo. Esta preocupação já tinha sido visível, nos finais da Monarquia Absoluta. No entanto, parece manter-se

8 SÁ, Isabel dos Guimarães e LOPES, Maria Antónia - História Breve..., cit., p. 75.

9 ASCMA, Actas das Sessões Ordinárias e Extraordinárias da Mesa da Irmandade da Santa Casa da Mizericordia de Arganil, livro 1, fl. 33v-34.

${ }^{10}$ SÁ, Isabel dos Guimarães e LOPES, Maria Antónia - História Breve ..., cit., p. 65-80. Ver também LOPES, Maria Antónia e PAIVA, José Pedro - Introdução in LOPES, Maria Antónia e PAIVA, José Pedro (dir.) - Portugaliae Monumenta Misericordiarum 7. Sob o signo da mudança: de D. José I a 1834. Lisboa: União das Misericórdias Portuguesas, 2008, p. 7-36

${ }^{11}$ SÁ, Isabel dos Guimarães e LOPES, Maria Antónia - História Breve..., cit., p. 78-80.

${ }^{12}$ ELIAS, Luís Filipe - A Misericórdia de Coimbra. Os Irmãos, as suas práticas e a intervenção régia (1749-1784), tese de mestrado, FLUC, 2006, p. 102 e 98-102. 
num contexto de Monarquia Constitucional, de que é exemplo a lei de 22 de Junho de 1866 para a desamortização dos bens das misericórdias inserida no propósito dos governos oitocentistas ${ }^{13}$.

Na segunda metade e nos finais do século XIX irá verificar-se em diversas misericórdias a efectivação de novos compromissos, demonstrando uma certa "democratização", a par da que se afere no país na mesma altura. Esta torna-se tangível em Arganil na extinção da divisão entre confrades de primeira e segunda condição e na admissão de mulheres, até então proibida, como consta no compromisso de 1843: «O mesmo que fica establecido para os Irmãos, será aplicável ás Irmaãs, que houverem d'entrár» ${ }^{14}$.

\section{Contexto num âmbito local}

A par da contextualização interna e externa das Santas Casas da Misericórdia em geral, e da Santa Casa de Arganil em particular, será também oportuna uma caracterização da localidade de Arganil no século XIX.

Rui Cascão qualificou Arganil deste período como uma "zona periférica» ${ }^{15}$ devido ao seu débil desenvolvimento económico e social. Aliado a essa condição, está o estado conjuntural do país que vai trazer à localidade acrescidas dificuldades alimentares e uma elevada taxa de mortalidade. Esta configuração irá levar a queixas do administrador do concelho ao nível da assistência pública prestada. Referindo-se às Misericórdias de Vila Cova e de Arganil, afirmava ele em Julho de 1861:

«a sua Administração não andam [sic] com as regularidades precisas; estes estabelecimentos têm sido ao desprezo pelas diversas auctoridades (...) consumindo a maior parte dos mesmos [rendimentos] em festas, e luxos, que ainda ate certo ponto precizos, são contudo necessidades secundárias, que devião ceder o seu lugar a outras muitas, que julgo

${ }^{13}$ Sobre este assunto ver SÁ, Isabel dos Guimarães e LOPES, Maria Antónia - História Breve..., cit., p. 65-92.

${ }^{14}$ ASCMA, Compromisso da Irmandade da Mizericordia de Arganil [1843], livro 1, fl. 3 .

${ }^{15}$ CASCÃO, Rui - Aspectos sociais e económicos..., cit., p. 4. 
de primeira classe, como socorrer a pobresa e derramar a instrução, e outras muitas» ${ }^{16}$.

Maria Antónia Lopes atesta existir uma «assistência medíocre» por parte de algumas misericórdias, em contraste com a «opulência das cerimónias religiosas que insistiam em perpetuar» ${ }^{17}$, o que sucedia, notoriamente, em Arganil.

Quanto à actividade económica da região, o sector agrícola seria o mais importante, sem abstrair a complexidade da actividade comercial com variadas redes de trocas. Este sistema, próprio da estrutura de uma economia arcaica, provocava a privação de dinheiro no seu estado líquido, de que resultava uma exangue capacidade de capitalização. Era portanto a terra, ainda, o principal meio de criação de riqueza ${ }^{18}$.

A desigualdade das condições materiais de existência leva inevitavelmente à desigualdade social espelhada na distribuição dos indivíduos por sectores de actividades. Rui Cascão já estabeleceu essa distribuição entre 1860 e 1900. A agricultura englobava entre $80 \%$ a $85 \%$ da população activa. A indústria ocupava uma média de $10,2 \%$, a seguir o comércio e os transportes com 3,9\%, a administração e justiça com $0,62 \%$, o clero com $0,95 \%$ e as profissões liberais com $0,90 \%$. Apesar das profissões liberais serem o sector com menos indivíduos, foi aquele que mais aumentou entre 1860 e 1900 , de $0,41 \%$ para $1,39 \%{ }^{19}$.

Ao nível da distribuição da riqueza em Arganil, segundo o Autor que estamos a seguir, os bacharéis, também proprietários de terras, eram os de maior opulência e os negociantes encontram-se no grupo das médias fortunas. O clero estava igualmente bem colocado, logo a seguir. Por fim surgiam os artífices e, numa condição de grande precariedade, os que viviam unicamente do trabalho da terra ${ }^{20}$.

\footnotetext{
${ }^{16}$ Cit. a partir de CASCÃO, Rui - Aspectos sociais e económicos..., cit., p. 8-9.

${ }^{17}$ SÁ, Isabel dos Guimarães e LOPES, Maria Antónia - História Breve..., cit., p. 75.

${ }^{18}$ CASCÃO, Rui - Aspectos sociais e económicos..., cit., p. 14-35.

${ }^{19}$ CASCÃO, Rui - Aspectos sociais e económicos..., cit., p.10.

${ }^{20}$ CASCÃO, Rui - Aspectos sociais e económicos..., cit., 17-26.
} 
Importa referir que os grupos mais bem situados à escala económica eram-no também à escala social, o que justifica que membros eleitos para a Câmara ou para o Conselho Municipal pertencessem ao grupo dos grandes proprietários $^{21}$. A constituição vintista ditou a riqueza como a afirmação das capacidades de cada um: os mais ricos seriam os melhores e os capazes de exercer o poder ou conduzir a comunidade ${ }^{22}$. Como tal, será interessante verificar de que forma esta mentalidade interferiu na eleição dos que chefiaram a Misericórdia e se a capacidade económica foi ou não uma condicionante ou um requisito.

\section{Os Provedores dirigentes da Misericórdia de Arganil no século XIX}

O provedor é o primeiro responsável pela administração da Santa Casa da Misericórdia. Segundo o compromisso de 1647 da Santa Casa da Misericórdia de Arganil, que se manteve em vigor até 1843, o provedor deveria ser uma pessoa com autoridade, prudência e virtude para que a irmandade $o$ reconhecesse como líder. Teria de ser, igualmente, uma pessoa nobre, com o mínimo de vinte e cinco anos de idade e ter passado um ano depois da sua entrada como irmão ${ }^{23}$. Assim sendo, além das particularidades exigidas a qualquer provedor, teria de ultrapassar o processo selectivo e restritivo de entrada de qualquer irmão.

«O Irmaõ que houver de ser admitido, terá sido de vida exemplár, limpo de maõs, caritativo, e temente a Deos./ Terá quatorze annos de idade completos. /Possuirá bens sofficientes de raiz para pagar a sua entrada e annual, e para poder occorrêr ás percisoens da Irmandade (...) Naõ deverá ser admitido para Irmaõ o que tivér má nota no conceito

${ }^{21}$ CASCÃO, Rui - Aspectos sociais e económicos..., cit., p.12.

${ }^{22}$ VIEIRA, Benedicta Maria Duque - A sociedade: configuração e estrutura in MARQUES, A. H. Oliveira (coord.) - Portugal e a Instauração do Liberalismo, vol. IX de Nova História de Portugal dir. por Joel Serrão e A. H. Oliveira Marques. Lisboa: Editorial Presença, 2002, p. 161-163.

${ }^{23}$ ASCMA, Compromisso da Irmandade da Mizericordia de Arganil [1647] livro 1, fl. $6 \mathrm{v}$. 
publico, ou que tivér commetido delicto infamante, ou que em juizo fôsse delle convencido; nem o que tivér molestia contagióza, alêijão, ou notavel deformidáde» $\left(\text { cap. } 1^{\circ}\right)^{24}$.

Quem almejasse ser irmão da Misericórdia tinha de, posteriormente, apresentar o seu requerimento ao provedor que o proporia à Mesa e «pela maioria dos votos por escrutínio secréto d'esféras brancas, e prêtas $\rangle^{25}$, a Mesa decidia se devia ser admitido.

É assim perceptível uma selectividade exigente em aspectos económicos, sociais, religiosos e físicos. Ao provedor estavam ainda acrescidas determinadas características ético-morais e o reconhecimento delas.

\section{Funções e poder simbólico de Provedor}

A exigência selectiva de acesso ao cargo está associada às obrigações a serem cumpridas por aquele que ascender a ele. Segundo o compromisso de $1843^{26}$, o provedor tem o direito e dever de dirigir a irmandade «promovendo a boa ordem, e o socêgo ${ }^{27}$. Tem ainda o direito e o dever de, no caso da ausência longa ou doença de um mesário, convocar os que se seguem a ele em número de votos da eleição correspondente, decidindo aquele que substitui o ausente. Tem o poder de reunir a Mesa ou a Irmandade quando considerar necessário, de ordenar ao escrivão que aponte a presença dos irmãos nas ocasiões em que devem comparecer. Tem o dever de se informar relativamente àqueles que pretendem entrar como irmãos, de ordenar a esmola até duzentos réis e sendo mais avultada é obrigado a consultar a Mesa;

${ }^{24}$ Idem, ibidem, fl. 1v. Existem alterações num posterior compromisso, mas apenas em termos de idade permitida para se poder exercer o cargo. A partir do de 1882, o provedor teria de ter vinte e um anos de idade (ASCMA, Compromisso da Irmandade da Mizeriscordia de Arganil [1647], livro 3, fl. 8v.).

${ }^{25}$ ASCMA, Compromisso da Irmandade da Mizericordia de Arganil [1647], livro 1, fl. $1 \mathrm{v}-2$.

${ }^{26}$ ASCMA, Compromisso da Irmandade da Mizeriscordia de Arganil [1843], livro 1, fl. $6 \mathrm{v} .-7 \mathrm{v}$.

${ }^{27}$ ASCMA, Compromisso da Irmandade da Mizeriscordia de Arganil [1843], livro 1, fl. $6 \mathrm{v}$. 
o dever de condenar todos os irmãos que faltarem sem justificação às suas obrigações, o direito e dever de presidir às Mesas, dirigindo os trabalhos, e em caso de votações decidir por voto de qualidade quando houvesse empate. É a ele que compete «mandar assentar, votar e calar quando the convier e todos obedecerão ${ }^{28}$. Compete-lhe ainda reunir a Irmandade para os enterros, devendo promover a decência do acto, pagar aos eclesiásticos e ao capelão quando necessário. Tem o direito a uma chave do arquivo, sendo considerado o primeiro fiscal da Irmandade. No compromisso de 1882 foi acrescida mais uma competência ao provedor: o poder de multar os oficiais da Mesa que, depois de avisados, faltassem sem justificação ${ }^{29}$.

Não só lhe era atribuído um forte poder decisivo no seio da Irmandade, através dos seus deveres e dos seus direitos, como detinha um concentrado poder simbólico ${ }^{30}$. O provedor tinha o dever, em todas as procissões solenes, de levar «a sua Vára de Gôverno logo adiante do Pálio, ou do Féretro» ${ }^{31}$. A vara de governo, que simbolizava o seu poder, era desfilada em cerimónia, além de que, nas procissões, o provedor ocupava o lugar à frente do pálio, e quanto mais perto se estivesse dele, mais proeminente se era.

\section{Grupos sociais de destaque}

Os aspectos mencionados como a selectividade no acesso ao cargo, o poder decisório de quem o alcança e a carga simbólica que este detém, permite perceber porque está ele reservado a uma elite local. Assim como afirma José Manuel Sobral, «Tal restringia o poder de decisão a uma

${ }^{28}$ Idem, ibidem.

${ }^{29}$ ASCMA, Compromisso da Irmandade da Mizeriscordia de Arganil [1882], livro 3, fl. 9.

${ }^{30}$ LOPES, Maria Antónia - Provedores e escrivães da Misericórdia de Coimbra de 1700 a 1910. Elites e Fontes de Poder. Revista Portuguesa de História. 36 (2º), (2002/2003), p. 217

${ }^{31}$ ASCMA, Compromisso da Irmandade da Mizericordia de Arganil [1843], livro 1, fl. 7. 
minoria $\rangle^{32}$. Importa, portanto, averiguar que elite predomina nas chefias da Santa Casa da Misericórdia de Arganil.

Ao ser analisada a lista de provedores que dirigiram a irmandade, primeiramente entre 1797 e 1831, deparamo-nos com uma presença maioritária de militares (50\%), indivíduos pertencentes a famílias nobres da região. Dentro deste grupo existem ainda dois desconhecidos $(33 \%)^{33} \mathrm{e}$ um sacerdote $(17 \%)$.

É fundamental considerar-se, perante isto, que no Antigo Regime a nobreza era muito abrangente, pois incluía os proprietários que viviam das suas rendas, oficiais militares, licenciados, negociantes matriculados, e no limite, segundo Francisco Vasconcelos, «todos os que possuíam cavalo e não tinham ofícios mecânicos» ${ }^{34}$. Até ao século XIX, nobreza era a designação que incluía toda a classe dirigente, independentemente de ser ou não hereditária, de ter ou não posses económicas. No final do Antigo Regime, começa a utilizar-se a designação de "classe média" pois a palavra nobreza era apenas para a hereditária. A explicação dessa alteração, para Francisco Vasconcelos, está na perda de força social da aristocracia fechando-se na sua hereditariedade ${ }^{35}$.

Podemos afirmar, diante disto, que estamos numa fase de transição em que, por um lado, ainda permanecem oficiais militares nobres com uma participação activa em lugares de destaque na sociedade e que, por outro lado, estes aristocratas deixam de usar os seus títulos ou qualquer qualificação nobiliárquica.

Dentro deste grupo de provedores estão José Feliciano de Melo Godinho Bulhões, José de Melo Freire de Bulhões Castelo Branco e João Saraiva Quaresma Caldeira, por esta ordem. José Feliciano de Melo Godinho

${ }^{32}$ SOBRAL, José Manuel - Religião, relações sociais e poder - a Misericórdia de F. no seu espaço social e religioso. Análise Social. Vol. 25, nº 107 (1990), p. 356.

${ }^{33}$ Desconhecidos são aqueles dos quais se sabe apenas o nome, desconhecendo-se o estrato social a que pertenceram.

${ }^{34}$ VASCONCELOS, Francisco - Alterações na nobreza no último século da monarquia in VIEIRA, Benedicta Maria Duque (coord.) - Grupos e estratificação social em Portugal no século XIX. Lisboa: Centro de Estudos de História Contemporânea Portuguesa, 2004, p. $100-101$.

${ }^{35}$ Idem, ibidem, p. 103. 
Bulhões foi capitão-mor ${ }^{36} \mathrm{e}$ na igreja matriz de Arganil encontra-se a capela da família Melo de Bulhões onde José Feliciano aparece como marido de D. Teresa Rita Freire de Vasconcelos Castelo Branco e mencionado como último visconde e conde da Quinta das Canas $^{37}$. É, portanto, clara a sua ascendência aristocrática. E tudo indica que José de Melo Freire de Bulhões Castelo Branco descendesse dessa mesma família, ao que acresce ter sido coronel do regimento das milícias da comarca de Arganil e fidalgo da Casa Real $^{38}$. João Saraiva Quaresma Caldeira foi capitão ${ }^{39}$.

Tal como Maria Antónia Lopes concluiu para Coimbra desta época ${ }^{40}$, em Arganil parece existir uma tendência para a hereditariedade do cargo, numa altura em que a Coroa não interferiu na eleição do provedor.

O sacerdote que dirigiu a Misericórdia neste primeiro período foi Francisco Saraiva Quaresma Caldeira, que parece ser o limiar da tendência que se irá seguir. Os dois desconhecidos foram Joaquim da Fonseca Figueiredo e João Antunes de Oliveira Leite.

Numa segunda fase de análise, desta vez entre 1831 a 1874, as alterações são significativas. Neste período a maioria dos provedores é constituída por clérigos (46\%). Existe ainda um doutor $(7 \%)^{41}$, um proprietário $(7 \%) \mathrm{e}$ seis desconhecidos (40\%). Os sacerdotes são Manuel Saraiva Quaresma de Oliveira, Francisco Ribeiro Barata, Manuel da Costa Vasconcelos Delgado, António Joaquim Ribeiro de Campos, António Joaquim de Paula, Luís Caetano Lobo, Joaquim Inácio da Costa Vasconcelos.

É possível uma referência biográfica apenas a duas individualidades deste grupo, Manuel da Costa e Luís Caetano, por terem sido estudadas por Amândio Galvão ${ }^{42}$. O primeiro, Manuel da Costa Vasconcelos Delgado, nasceu em Arganil a 28 de Outubro de 1790 no seio de uma família

${ }^{36}$ ASCMA, Eleições e determinações, livro 1, fl. $7 \mathrm{v}-8$.

${ }^{37}$ SIMÕES, Alberto Veiga - Arganil in Ilustração Portuguesa. 10 de Dezembro de 1906, p. 604. Para informação mais detalhada da capela dos Melos ver ANACLETO, Regina Arganil. Lisboa: Editorial Presença, 1996.

${ }^{38}$ ASCMA, Eleições e Determinações, livro 1, fl. 116-117.

${ }^{39}$ Idem, ibidem, fl. 152-153.

${ }^{40}$ LOPES, Maria Antónia - Provedores e escrivães..., cit., p. 222.

${ }^{41} \mathrm{O}$ provedor aparece mencionado com Dr. antes do nome. Não foi possível apurar se seria doutorado ou bacharel.

${ }^{42}$ GALVÃO, Amândio - Figuras Notáveis de Arganil. Arganil: Câmara Municipal, 1991. A informação recolhida nesta obra merece algumas reservas. 
aristocrática, o seu pai era um grande proprietário e dono das maiores casas agrícolas de Arganil. Iniciou os seus estudos na vila e, posteriormente, frequentou o Seminário em Coimbra, regressando a Arganil em 1814. A 14 de Junho de 1825 foi nomeado reitor da igreja paroquial e colegiada de Arganil, já com 35 anos de idade, e foi provedor da Misericórdia em 1842-44, 1845-47 e 1855-56. Faleceu no dia 23 de Maio de 1856.

Luís Caetano Francisco António Jerónimo Vicente Guilherme de Santa Ana Lobo, era indiano, nascido em Goa a 24 de Julho de 1816. Pertencia à alta aristocracia indiana. A sua família converteu-se ao catolicismo e por isso iniciou estudos no seminário em Goa. Seguiu depois para Coimbra para se formar em Teologia, terminando o bacharelato em 1845. Doutorou-se em Leis aos 35 anos em $1851^{43}$ e chegou mesmo a dar aulas na Faculdade, mas foi impedido de chegar a lente. Iniciou, por isso, a sua vida eclesiástica e em 1856, com o falecimento do reitor da vila de Arganil, Manuel da Costa Vasconcelos Delgado, foi convidado para ocupar o seu lugar, o que fez em 1857. Foi provedor da Misericórdia a 1858-61, 1870-71 e 1873-74 e chegou também a exercer advocacia na região. Faleceu a 29 de Novembro de 1890.

Importa considerar, nesta matéria, a evolução das relações entre o Estado e a Igreja neste período. A secularização do Estado e da sociedade trouxe ao clero algumas dificuldades que se vão fazer sentir ao longo do século XIX. Miguel Santos refere-se à legislação desamortizadora, como o dízimo, que irá reforçar a dependência económica do clero, ao que se associa desprestígio social ${ }^{44}$. Ana Mouta Faria acrescenta dificuldades de recrutamento e uma ignorância generalizada. Estas perturbações levam o clero a ganhar um novo perfil e estatuto, definido em função do serviço da religião e legitimado por este mesmo serviço ${ }^{45}$. Este contex to permite-nos compreender as razões

\footnotetext{
${ }^{43}$ Apesar de Luís Caetano Lobo ser bacharel e doutorado, está inserido no conjunto dos eclesiásticos eleitos provedores porque a maioria da sua acção profissional é direccionada nessa vertente.

${ }^{44}$ SANTOS, Miguel - O Clero in SOUSA, Fernando e MARQUES, A. H. Oliveira (coord.) - Portugal e a Regeneração, vol. X de Nova História de Portugal dir. por Joel Serrão e A. H. Oliveira Marques. Lisboa: Editorial Presença, 2004, p. 149-157.

${ }^{45}$ FARIA, Ana Mouta - O Clero em mudança, do Antigo Regime para o Liberalismo (1820-1930): demografia, representações e problemas de classificação social (de ordem a corpo profissional) in VIEIRA, Benedicta Maria Duque (coord.) - Grupos e estratificação social em Portugal no século XIX. Lisboa: Centro de Estudos de História Contemporânea Portuguesa, 2004, p. 81-82.
} 
que potenciaram uma acessão em massa a um cargo tão relevante por parte desta categoria profissional.

José Joaquim Jorge foi o único provedor com o título de doutor. Em igual período, na Misericórdia de Coimbra, verificou-se um forte crescimento da carreira académica enquanto geradora de provedores ${ }^{46}$. Este panorama não se verifica tão intensamente em Arganil, mas a inserção deste provedor permite perceber que o grau académico começa a adquirir uma consideração acrescida. O provedor Bernardo José Simões era proprietário ${ }^{47}$. Sendo este um grande proprietário, justifica-se que fizesse parte da elite local.

Como provedores desconhecidos estão José da Costa Gomes, Joaquim da Fonseca Figueiredo, João Antunes Tavares, António José Coelho Sénior, Francisco José Jorge e Manuel Jorge Rodrigues.

$\mathrm{Na}$ terceira e última fase de análise, entre 1874 e 1900, revela-se, novamente, outra alteração do quadro social da lista de provedores. Os que se evidenciam em maior número são os doutores (38\%), seguidos dos negociantes $(25 \%)$ e dos eclesiásticos (25\%). Existe ainda um proprietário (12\%) e não se registam desconhecidos. É, portanto visível, nesta fase, uma maior distribuição da escolha dos provedores pelos diferentes grupos sociais e revela-se, igualmente, uma maior frequência de estratos sociais em ascensão, como é o caso dos negociantes. Estes começam a adquirir relevo social, uma vez que é um grupo que cada vez mais se destaca pelo seu grau de riqueza ${ }^{48}$.

Os provedores referidos com o título de doutor são José da Costa Vasconcelos Delgado, Augusto de Oliveira Coimbra e António Gomes da Silva Sanches ${ }^{49}$. Os negociantes são João Travassos ${ }^{50}$, e José Augusto de Carvalho $^{51}$. Os padres são António Joaquim de Paula e Joaquim Inácio da

${ }^{46}$ LOPES, Maria Antónia - Provedores e escrivães..., cit., p. 232.

${ }^{47}$ CALDEIRA, José - A família Arganilense de Veiga Simões. Arganilia. No 1, 1992, p. 51-65.

${ }^{48}$ SANTOS, Miguel e CRUZ, Maria Antonieta - A sociedade, in SOUSA, Fernando e MARQUES, A. H. Oliveira (coord.) - Portugal e a Regeneração, cit., p. 169.

${ }^{49} \mathrm{O}$ provedor António Gomes aparece mencionado com Dr. antes do nome, no entanto, não foi possível apurar se seria doutorado, bacharel ou médico.

${ }^{50}$ ASCMA, Actas das Sessões Ordinárias e Extraordinárias..., cit., livro 1, fl. 174-174v.

${ }^{51}$ Idem, ibidem, fl. 32-33. 
Costa Vasconcelos e o referido proprietário é Francisco António Maria da Veiga.

Podemos, em suma, verificar que os eclesiásticos são aqueles que ao longo do século XIX mais são eleitos para o cargo de provedor na Misericórdia de Arganil, os segundos mais eleitos são os doutores e seguidamente os militares. São estes diferentes grupos, que nas distintas fases analisadas, e respectivamente, se transformam na maioria. Como se justificaria essa primazia? É compreensível que, numa primeira fase, se mantenha a lógica de Antigo Regime em que a aristocracia abrange uma elevada relevância ao nível do poder local. Porém, a maioria dos provedores de prosápia nobre são militares, o que revela a cada vez maior secundarização da nobreza pela perda de força social, uma vez que a condição militar se tornou a mais ambicionada pelos grupos da pequena aristocracia ou da nobreza empobrecida ${ }^{52}$. Convém, contudo, ponderar que no discurso liberal as qualificações de "homem nobre" ou de cavaleiro caem em desuso e que as mesmas pessoas passam a intitular-se proprietários como aqueles que possuem bens imóveis ${ }^{53}$. A atenção a este fenómeno possibilita uma diferente análise dos provedores supracitados intitulados proprietários. Obriga a considerar que a presença nobre na direcção da Misericórdia esteja em maioria só no início do século. Ter-se-á mantido ao longo do período, embora em minoria.

Os eclesiásticos são a maioria ao longo de todo o século, mas é entre 1831-74 que granjeiam destaque. Como foi referido anteriormente, o clero vai sofrer um desprestígio social significativo, associado à diminuição do seu poder económico. No entanto, a influência moral exercida pelo clero paroquial sobre as populações locais mantinha-se em níveis elevados ${ }^{54}$. Tal como afirma Ana Mouta Faria «O clero paroquial é, de longe, de entre os estratos eclesiásticos, o mais valorizado. Facto devido à importância atribuída à proximidade dos leigos, ao serviço de quem se encontra» ${ }^{55}$.

${ }^{52}$ VIEIRA, Benedicta Maria Duque - A sociedade: configuração e estrutura, cit., p. 191.

${ }^{53}$ Segundo Francisco Vasconcelos passa a existir, no século XIX, uma nobreza oculta escondida por identificações profissionais, o que faz com que seja difícil perceber a sua real participação na sociedade (VASCONCELOS, Francisco - Alterações na nobreza..., cit., p. 101).

${ }^{54}$ SANTOS, Miguel e CRUZ, Maria Antonieta - A sociedade..., cit., p. 153.

${ }^{55}$ FARIA, Ana Mouta - O Clero em mudança..., cit., p. 94. 
No período subsequente vão destacar-se os doutores. Este número atesta o valor que era atribuído à instrução no contributo para o desenvolvimento económico e para o aperfeiçoamento de cada $u^{56}$.

Uma percentagem numericamente relevante é a de desconhecidos, principalmente na segunda fase analisada, impossibilitando uma correcta análise desse período.

As mudanças das elites dirigentes da Misericórdia de Arganil significam, além de transformações do contexto social, cultural, económico, político e religioso de então, uma patente alteração das motivações para a busca do cargo de provedor.

Desde as últimas décadas de Setecentos que se verificava a perda de atractivos pelo cargo por parte da nobreza, o que foi provocado, provavelmente, pela sucessiva e crescente dificuldade no acesso ao crédito e a pressão que se intensificou para o pagamento dos juros desses empréstimos, com o intuito de colmatar as dificuldades financeiras das misericórdias ${ }^{57}$.

Em Arganil, José de Melo Freire de Bulhões Castelo Branco recusou ser provedor da Misericórdia a 16 de Julho de $1826^{58}$. Mais tarde, outros dois provedores pretenderam demitir-se do cargo, como é o caso do Reverendo Francisco Ribeiro Barata a 16 de Abril de $1837^{59}$ e do Reverendo António Joaquim de Paula a 23 de Março de $1885^{60}$. Não foi possível apurar as razões dessas tomadas de decisão.

Por outro lado, o prestígio, poder e visibilidade social eram sem dúvida grandes motivações para os grupos em processo de ascensão, como é o caso dos negociantes que, apesar de economicamente abastados, não tinham um estatuto social correspondente, adquirindo desta forma a honorabilidade almejada $^{61}$. Seria também esse o motivo do interesse pela chefia da parte dos eclesiásticos: o cargo permitia-lhes um acréscimo ao estatuto e um acesso aos rendimentos da instituição, a par de outras regalias constantes dos

\footnotetext{
${ }^{56}$ Ver SANTOS, Miguel e CRUZ, Maria Antonieta - A sociedade, cit., p. 167.

${ }^{57}$ LOPES, Maria Antónia - Provedores e escrivães..., cit., p. 228.

${ }^{58}$ ASCMA, Eleições e Determinações, livro 1, fl. 114-115v.

${ }^{59}$ ASCMA, Eleições e Determinações, livro 2, fl. 43-43v.

${ }^{60}$ ASCMA, Actas das Sessões Ordinárias e Extraordinárias..., cit., livro 4, fl. 35-36v.

${ }^{61}$ LOPES, Maria Antónia - Provedores e escrivães..., cit., p. 236.
} 
direitos do provedor. Assim, mais uma vez como em Coimbra, é manifesta a permanência de capacidades atractivas da Misericórdia durante o século XIX.

\section{Relações, poderes e conflitualidades}

\section{Rotatividade nos cargos e mandatos}

Como se apurou anteriormente, as elites dirigentes da Misericórdia de Arganil foram-se alterando. Esse facto levaria a pensar que não seria possível permanecer uma oligarquia restrita na chefia da Santa Casa. Contudo, após uma análise direccionada para os anos de mandatos de cada provedor, foi possível aferir o oposto.

Numa primeira fase (1797-1831), a média de anos de mandato por provedor é de seis, no período seguinte (1831-1874) baixa para três anos e na última época (1874-1900) a média é de quatro anos. Estes dados proporcionam avaliar que, reduzindo-se o número de anos de mandatos, permitiu-se uma maior rotatividade entre os provedores eleitos. No entanto, este cotejo não permite concluir se subsistiria uma determinada oligarquia na Misericórdia. Tal comprovou-se possível através do número de vezes que cada provedor foi eleito. Na primeira fase foram-no, em média, uma vez, mas nos segundo e terceiro períodos a média subiu para duas vezes ${ }^{62}$, chegando a encontrar-se provedores a serem eleitos cinco vezes. Existiu, portanto, na Misericórdia de Arganil do século XIX, não só um evidente aumento da rotatividade nas eleições dos provedores, como também uma manifesta presença dos mesmos indivíduos que reaparecem e se sucedem constantemente. Esse facto é justificável se se atentar que, além do cargo de provedor estar restrito a uma elite, e portanto, a uma minoria, Arganil, como foi referido, era uma região periférica, logo, essa minoria tornar-se-ia ainda mais restrita.

Importa ainda verificar que no primeiro período, não só é manifesta a presença de uma rede familiar, como também é visível um elevadíssimo número de mandatos exercidos pela mesma pessoa, chegando mesmo aos

\footnotetext{
${ }^{62}$ LOPES, Maria Antónia - Provedores e escrivães..., cit., p. 236.
} 
quinze anos ${ }^{63}$. A justificação encontra-se novamente no domínio da nobreza a um âmbito local, à semelhança do que sucederia no Antigo Regime.

Outro aspecto que merece destaque no âmbito da rotatividade dos mandatos, é o de terem existido casos em que o Governo central teve um carácter activo na nomeação do provedor, interrompendo e impedindo que os mandatos se concluíssem naturalmente. Este aspecto atesta o carácter intervencionista adoptado pela Coroa em relação às misericórdias neste período. Uma nomeação desse tipo foi executada no mandato do provedor Bernardo José Simões, em 1869/1870, e outra no de José de Costa Vasconcelos Delgado, em 1886/1887 ${ }^{64}$. Foi sempre nomeado pela Coroa como presidente da comissão administrativa da Santa Casa o Reverendo Joaquim Inácio da Costa Vasconcelos, que foi procurador nos anos 1862 a 1865, provedor entre 1865 e 1867 e por altura do mandato de Bernardo José Simões foi também secretário, ascendendo a presidente no dia 8 de Junho de $1870^{65}$. Decorridos dezassete anos, volta a ser novamente nomeado para presidente a 13 de Fevereiro de $1887^{66}$.

Comprovada a rotatividade nos mandatos dos provedores, importa aferir se a ocupação do cargo de provedor se constituía como uma promoção interna, isto é, se haveria uma acumulada ocupação dos restantes cargos da Mesa até se chegar ao topo. Numa análise feita às Mesas que presidiram à Santa Casa no período em análise, verifica-se que aqueles que chegaram a provedores foram na maioria das vezes ocupando cargos da Mesa tanto antes como depois de o serem, numa percentagem de $46 \%$. A percentagem daqueles que apenas ocupam cargos antes de serem provedores é de 25\%. Cerca de $12 \%$ exercem os restantes cargos da Mesa depois da chefia e uma percentagem de $17 \%$ não ocupou mais nenhum cargo. Não foi, todavia, detectado um padrão no tipo de cargos exercidos antes de se ser provedor ou depois. Verificou-se ser muito variado o tipo de trajectória que se fazia dentro da instituição.

\footnotetext{
${ }^{63}$ Refiro-me aos anos de mandato de José de Melo Freire de Bulhões Castelo Branco.

${ }^{64}$ Apenas 5\% dos mandatos foram de nomeação governamental.

${ }^{65}$ ASCMA, Actas das Sessões Ordinárias e Extraordinárias ..., cit., livro 5, fl. 172-173.

${ }^{66}$ Idem, ibidem, fl. $19 \mathrm{v}-20 \mathrm{v}$.
} 
Aqueles que vão ocupando cargos, tanto antes como depois exercício da provedoria, são também aqueles que mais vezes foram eleitos provedores. Esta evidência coloca em destaque a valorização que era atribuída aos que, através da ocupação de cargos, obtinham um estatuto dentro da Misericórdia. Desta mesma forma se justificam os $25 \%$ dos que haviam já desempenhado cargos na Mesa antes da chefia, pois permitira-lhes demonstrar capacidades para que a irmandade os «reconhecesse seo chefe», como se afirma em sessão de $1870^{67}$. Aqueles que exerceram posteriormente outros cargos da Mesa, seria por terem adquirido um estatuto que lho permitia.

Apesar da experiência e do estatuto que se adquiriam internamente terem constatável relevância, existiram provedores que desempenharam a sua chefia sem nenhum histórico e sem continuação no comando da Santa Casas. Um desses casos foi o de Francisco Saraiva Quaresma da Caldeira, provedor em 1821-22, de que se sabe apenas ser eclesiástico. Também o de António Gomes da Silva Sanches que, segundo a acta de 4 de Outubro de 1891, terá «sido elleito Provedor por influencia e sugestão d'alguns seos

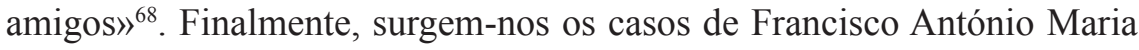
da Veiga, provedor entre 1874-1881, e José da Costa Vasconcelos Delgado, provedor em 1888-89,1891-92,1893-95 e 1897-99, que têm em comum a ocupação de cargos na Câmara Municipal de Arganil. O primeiro vem referido na acta de 20 de Julho de 1874 como tendo sido vogal do Conselho Municipal ${ }^{69}$ e o segundo foi presidente da Câmara nos anos de 1870, 1872, $1876,1878,1880,1884$ e $1886^{70}$. Assim sendo, ambos desempenharam as suas actividades na Câmara durante o mandato na Santa Casa. Essa atitude permitiria justificar a sua intervenção pontual na Irmandade pela intenção de permanecer em actividade na Câmara. $\mathrm{O}$ facto de terem ocupado o lugar máximo da Misericórdia sem qualquer actividade prévia relevante, só pode explicar-se pelo reconhecimento social de que gozavam na vila e que à Santa Casa interessava.

${ }^{67}$ CASCMA, Actas das Sessões Ordinárias e Extraordinárias..., cit., livro 6, fl. $112 \mathrm{v}-113 \mathrm{v}$.

${ }^{68}$ Idem, ibidem, fl. $112 \mathrm{v}-113 \mathrm{v}$.

${ }^{69}$ Arquivo da Câmara Municipal de Arganil, Livro de Actas da Câmara Municipal de Arganil, livro 5, fl. 21.

${ }^{70}$ PIMENTEL - Presidentes e vice-presidentes da Câmara Municipal de Arganil desde 1834. A Comarca de Arganil, Arganil, 29 de Julho de 1971, p. 1-2. 


\section{Poderes autárquicos dos Provedores}

Tanto no Antigo Regime, como no Liberalismo, as Câmaras eram governadas pelas elites locais ${ }^{71}$. Sendo em Arganil essa elite bastante restrita, torna-se lógico que a mesma se encontre presente tanto na governação municipal como nas misericórdias, duas importantes instituições de poder local. Manuel Sobral refere para o caso da Misericórdia de F. essa ligação das famílias mais importantes da Santa Casa a outros órgãos políticos ${ }^{72}$ e o mesmo se verificava em Arganil de Oitocentos. João Antunes de Oliveira Leite, provedor entre 1824-1825 e 1828-1829, ocupou o cargo de administrador do concelho entre 1831-35. João Antunes Tavares, provedor entre 1840-42, tinha sido presidente da Câmara em 1838 e volta a sê-lo em 1840. António Joaquim Ribeiro de Campos, provedor entre 1844-1845, 1848-1850, 1851-1853, 1861-1862 e 1867-1868, foi vice-presidente da Câmara nos anos 1862, 1864, 1866 e 1868. Francisco José Jorge, provedor entre 1856-1857, foi presidente da Câmara em 1854 e vice-presidente em 1854 e 1858. Manuel Jorge Rodrigues, provedor entre 1872-1873 foi presidente em 1845. João Travasso, provedor entre 1885-1886 e 1887-1888, foi presidente da Câmara no ano de 1891. José da Costa Vasconcelos Delgado, provedor entre 1886-1887, 1888-1889, 1891-1892, 1893-1895, 1897-1899, foi presidente da Câmara nos anos de 1870, 1872, 1876, 1878, 1880,1884 e $1886^{73}$. Numa análise aos principais cargos ocupados na Câmara por membros da Santa Casa que chegaram a provedores, é possível apurar que, por um lado, a Câmara funcionava como meio de alcançar um estatuto social - para os grupos em ascensão neste período - que permitia a quem o conquistava ocupar lugares de notoriedade também na Misericórdia, e que, por outro lado, existia um cursus honorum com sentido inverso: a Misericórdia possibilitava um estatuto que levava aqueles que a chefiaram a usufruírem de um acesso facilitado a altos cargos da Câmara. O que

${ }^{71}$ MONTEIRO, Nuno Gonçalo Freitas - Elites e Poder. Lisboa: Imprensa das Ciências, 2003; PEREIRA, João - Elites locais e liberalismo. Torres Vedras, 1792-1878. Estudos Autárquicos, 6-7 (1996).

${ }^{72}$ SOBRAL, José Manuel - Religião, relações sociais e poder..., cit., p. 362-363.

${ }^{73}$ PIMENTEL - Presidentes e vice-presidentes..., cit., p. 1-2. 
não surpreende, uma vez que eram duas instituições decisivas ao nível do poder local ${ }^{74}$.

A ocupação de lugares na Câmara por membros que chefiaram a Santa Casa não se resumia aos altos cargos ${ }^{75}$. Existiu um total de catorze (58\%) em vinte e quatro provedores a ocupar lugares que variaram entre vereador, vogal, vogal suplente e tesoureiro. Dos dez homens que não desempenharam funções camarárias (42\%) seis eram eclesiásticos, talvez impedidos por questões profissionais, embora esses cargos não lhes fossem interditos e, de facto, alguns dos provedores anteriormente referidos com lugares na Câmara eram sacerdotes.

A relação que se descobre entre os dois organismos de poder local evidencia a crescente apropriação de poder que se alcançava através do exercício dos cargos tanto na Câmara como na Misericórdia.

\section{Relações de conflito}

Sendo as misericórdias instituições com grandes rendimentos e detentoras de prestígio que lhes permitia exercer, de facto, poder a um âmbito local, seria inusitado que não surgissem conflitos para se aceder aos mais altos cargos da sua governação.

Um género de conflitos muito comum em finais de Antigo Regime era o dos clérigos com as misericórdias. As suas relações não eram somente baseadas na ocupação de cargos de chefia uma vez que, em muitos casos, foram detectados conflitos entre os párocos e as misericórdias das pequenas localidades ${ }^{76}$. A Misericórdia de Arganil não foi excepção e segundo Regina Anacleto, em meados do século XVIII, são notórios os diferendos entre a autoridade religiosa e a Misericórdia ${ }^{77}$, os quais permanecem ao longo do século XIX. No dia 14 de Novembro de 1875 foi realizada uma reunião

${ }^{74}$ LOPES, Maria Antónia e PAIVA, José Pedro - Introdução, cit., p. 20.

${ }^{75}$ Foram analisados apenas os livros de actas da Câmara Municipal dos anos 1831 a 1835 , 1843 a 1845,1850 a 1852,1860 a 1864,1874 a 1877 e 1880 a 1883 o que impossibilita uma análise mais aprofundada das relações entre a Câmara e a Misericórdia, mas permite uma visão aproximada a esse nível.

${ }^{76}$ Cf. LOPES, Maria Antónia e PAIVA, José Pedro - Introdução, cit., p. 19.

77 ANACLETO, Regina - A Irmandade da Misericórdia de Arganil e a festa da Senhora da Conceição. A Comarca de Arganil, 7966 (18.10.1979). 
da Mesa a que presidiu o provedor Francisco António Maria da Veiga para que se lesse e respondesse a uma queixa feita pelo padre Joaquim Inácio da Costa Vasconcelos, dirigida ao governador civil do distrito, cuja cópia foi apresentada ao administrador do concelho ${ }^{78}$. Será relevante assinalar que o padre Joaquim Vasconcelos, nesta data, detinha um notável historial de carreira na Misericórdia, tendo sido procurador, secretário, provedor e presidente da comissão administrativa da Santa Casa.

Na queixa que elaborou alegava não serem realizados orçamentos anuais, nem terem sido concluídas as obras da albergaria, orçadas pela última comissão à qual presidira. Afirmava não serem cobradas as dívidas activas, acusando disso a Mesa em exercício e as anteriores, não serem registadas na conservatória algumas escrituras, e serem realizadas obras luxuosas e desnecessárias. Acusava ainda o provedor de não dirigir correctamente a Santa Casa, não cumprindo com as suas obrigações determinadas pelo compromisso. Por último, alegava serem emprestados a particulares bens móveis da Santa Casa. A todas as alegações do padre Joaquim Inácio Vasconcelos a Mesa respondeu agressivamente, chegando a acusá-lo de ter «muita ingerência nos negocios da Misericordia».

Estes conflitos patenteiam uma acesa disputa pelo controlo da Santa Casa que levava ao extremo das denúncias e, decerto não por acaso, se revelava numa altura em que se iniciava uma fase em que os sacerdotes deixavam de alcançar em tão elevado número o cargo de provedor, passando a existir uma hegemonia de doutores, negociantes e proprietários.

Apesar deste incidente, onze anos após a queixa que efectuou, Joaquim Inácio da Costa Vasconcelos foi nomeado presidente da comissão administrativa da Santa Casa. Como seria de esperar, surgiram mais queixas, revelando o desacordo que sua nomeação suscitava. António Ribeiro Mendes, proprietário e irmão da Misericórdia, terá afirmado «que na qualidade de Irmão da Sancta Casa da Mizericordia, não voltava aos actos da Irmandade em quanto la estivesse aquella quadrilha (referindo-se á Commissão), e que não punha os pez na Mizericordia, em quanto a mesma Commissão estivesse a foncionar» ${ }^{79}$.

\footnotetext{
${ }^{78}$ ASCMA, Actas das Sessões Ordinárias e Extraordinárias..., cit., livro 2, fl. 63-67v.

${ }^{79}$ ASCMA, Actas das Sessões Ordinárias e Extraordinárias..., cit., livro 5, fl. 37-37v.
} 
Em 1887 chegaram à comissão administrativa quatro ofícios do pároco da freguesia, queixando-se de desigualdade na atribuição de esmolas, de desinteresse pela Irmandade no acompanhamento dos funerais e de serem admitidas pessoas menos dignas para enfermeiros do hospital. Considerava-se escuso de determinadas obrigações de irmão devido às suas tarefas enquanto pároco e alegava estar isento de multas por esse incumprimento por ter sido provedor. Declarava ainda que a comissão tinha sido eleita para «se cortarem abusos que n'ella [Santa Casa] grassavam com escândalo publico - e era publico que eram incobertos pelas Mesas tranzactas, pelo favoritismo dos partidos $\rangle^{80}$.

As rivalidades verificavam-se sobretudo entre aqueles que eram nomeados pelo poder central para chefiar a Santa Casa e aqueles que eram eleitos no interior da instituição, o que demonstra que o controlo que os governos pretendiam exercer não era bem recebido e se revelava causador de conflitos.

\section{Conclusão}

A Misericórdia de Arganil reproduz as conjunturas sociais, económicas, políticas e administrativas do século XIX. Revela um evidente papel social na transmissão, às elites locais, de influência e de prestígio, através da ocupação dos cargos de chefia. Neste período, fecundo em transformações, verifica-se uma gradual ruptura da hegemonia nobiliárquica, facilitando a ascensão de novos grupos, como os negociantes e os licenciados, e permitindo uma maior distribuição, no acesso à provedoria, por diversas categorias profissionais, desde que detentoras de estatuto social considerado dignificante. Contudo, tal não foi sinónimo de "democratização", pois subsistiram oligarquias restritas. Simultaneamente, emerge intensa conflitualidade protagonizada pelo grupo que, em maior número, dominou o poder na Santa Casa durante o período considerado, o clero. Revela-se, assim, que a instituição continuava apelativa e que dominá-la era um objectivo almejado.

${ }^{80}$ Idem, ibidem, fl. $21 \mathrm{v}-22 \mathrm{v}$. 